\title{
A freeze-thaw method for disintegration of Escherichia coli cells producing T7 lysozyme used in pBAD expression systems
}

\author{
Marta Wanarska ${ }^{凶}$, Piotr Hildebrandt and Józef Kur \\ Department of Microbiology, Chemical Faculty, Gdańsk University of Technology, Gdańsk, Poland
}

Received: 08 August, 2007; revised: 10 September, 2007; accepted: 14 September, 2007

availabe on-line: 17 September, 2007

\begin{abstract}
The pLysN plasmid containing the T7 lysozyme gene under control of the lac promoter was constructed to facilitate cell disintegration after expression of recombinant proteins in arabinose-induced expression systems. The usefulness of this plasmid was tested in Escherichia coli TOP10 and E. coli LMG194 cells carrying pBADMHADgeSSB plasmid containing Deinococcus geothermalis SSB protein gene under control of the araBAD promoter. The results showed that low-level expression of T7 lysozyme did not interfere with the target SSB protein production, and that the freezing-thawing treatment was sufficient for disruption of the E. coli cells producing low amounts of T7 lysozyme.
\end{abstract}

Keywords: T7 lysozyme, disintegration, pBAD expression systems

Escherichia coli is the most frequently used prokaryotic expression system for production of heterologous proteins. However, efficient expression of different genes in E. coli is not a routine matter and requires a set of experiments for optimization of cultivation conditions such as induction time, inducer concentration and incubation time for maximum expression. Often, the samples must subsequently be analyzed by SDS/PAGE after lysis of the E. coli cells. Nowadays, several cell disruption methods are used (Bollag et al., 1996), but sonication or incubation with lysozyme from chicken egg play the main role in laboratory practice. All these methods are time consuming, and an easier and faster method is desired. The commercially available E. coli strains, like BL21(DE3)pLysS or Rosetta(DE3)pLysS, used in Novagen's pET System or T7 Expression Systems (Invitrogen) enable high-level expression of recombinant proteins and elimination of basal expression level. They are also designed for easier cell disruption after expression as they produce low amounts of T7 lysozyme (Studier, 1991). Unfortunately, there is no such option available for the pBAD expression systems. Therefore, we have developed self-lysing E. coli strains for the arabinose-induced expression systems. First, we constructed a pLysN plasmid (Fig. 1) that allowed expression of lysozyme T7 at low levels in bacterial cells. This plasmid was obtained using the pACYC184 cloning vector. The DNA fragment containing lac promoter and lac operator was amplified by PCR using the DNA of plasmid pUC19 as the template. The primers used were: PromS1 5'-GAGGATCGGTCGACGCGCAACGCAATTAATGTGA-3' and PromClys 5'-GTACACGAGCCATAGCTGTTTCCTGTGTGTGAAATTG-3'. For PCR amplification of the lysozyme T7 gene, the LysNprom 5'-GAAACAGCTATGGCTCGTGTACAGTTTAAACAACG-3' and LysCB1S1 5'-CAGT CGACGGATCCTTATCCACGGTCAGAAGTGACCAG-3' primers were used with the pLysS plasmid (Novagen) as the template. Both PCR products, diluted 250 times, were then mixed with primers PromS1 containing SalI recognition site (underlined) and LysCB1S1 containing SalI and BamHI recogni-

\footnotetext{
$\square$ Author for correspondence: Marta Wanarska, Department of Microbiology, Gdańsk University of Technology, Narutowicza 11/12, 80-952 Gdańsk, Poland; phone: (48 58) 347 2383, fax: (48 58) 347 0294, e-mail: martka.chem@wp.pl Abbreviations: SSB, single-stranded DNA-binding; DgeSSB, single-stranded DNA-binding protein from Deinococcus geothermalis; LB medium, Luria-Bertani medium; SDS/PAGE, SDS/polyacrylamide gel electrophoresis.
} 


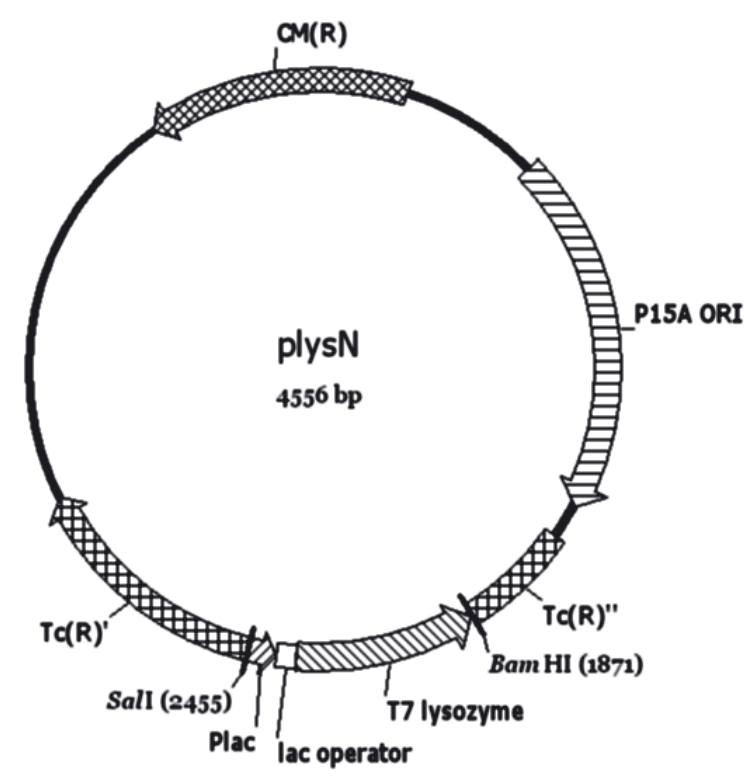

Figure 1. Map of the pLysN plasmid.

tion sites (underlined) and used in a PCR reaction to obtain the DNA fragment for cloning. Following SalI and BamHI digestion this DNA fragment, containing the T7 lysozyme gene under control of the lac promoter, was cloned into the pACYC184 vector digested with the same restriction enzymes. Next, competent cells of E. coli TOP10 (Invitrogen) or LMG194 (Invitrogen) strains (the most frequently used hosts for protein expression in arabinose-induced expression systems) were transformed with the constructed pLysN plasmid. These strains displayed a low-level production of T7 lysozyme when cultivated in LB medium (Fig. 2). The lysozyme was expressed constitutively since E. coli TOP10 and E. coli LMG194 strains do not contain the entire lac operon or the lacI gene encoding the LacI repressor ( $\triangle l a c X 74$ strains).

To test the usefulness of the constructed strains in an arabinose-induced expression system, competent cells of E. coli TOP10 or LMG194 strains containing the pLysN plasmid were transformed with the pBADMHADgeSSB plasmid (Filipkowski et al., 2006), carrying Deinococcus geothermalis SSB protein gene under control of the araBAD promoter. The same bacterial strains without the pLysN plasmid were used as expression controls. Fifty milliliters of the bacterial cultures were grown to mid-log phase $\left(\mathrm{OD}_{600} 0.5\right)$ and the expression was induced with $0.2 \%$ of L-arabinose for $12 \mathrm{~h}$. Two milliliters of each cell suspension was centrifuged, and the pellets were resuspended in $100 \mu \mathrm{l}$ of $20 \mathrm{mM}$ Tris/ $\mathrm{HCl}, \mathrm{pH}$ 7.5 and placed at $-20^{\circ} \mathrm{C}$ for $15 \mathrm{~min}$. After thawing at room temperature, the samples were centrifuged and $20 \mu \mathrm{l}$ samples of the supernatants were separated by

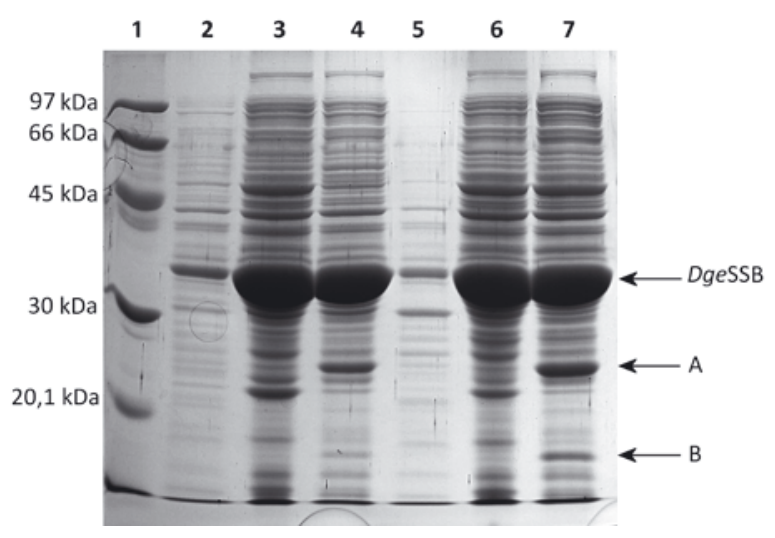

Figure 2. SDS/PAGE analysis of soluble fractions of cell lysates obtained after expression of the recombinant DgeSSB protein.

Electrophoresis in 15\% polyacrylamide gel by the method of Laemmli. 1. LMW SDS marker (Amersham Biosciences AB, Uppsala, Sweden); 2. E. coli TOP10 + pBADMHADgeSSB frozen and thawed; 3. E. coli TOP10 + pBADMHADgeSSB sonicated; 4. E. coli TOP10 + pLysN+ pBADMHADgeSSB frozen and thawed; 5. E. coli LMG194 + pBADMHADgeSSB frozen and thawed; 6. E. coli LMG194 + pBADMHADgeSSB sonicated; 7. E. coli LMG194 + pLysN + pBADMHADgeSSB frozen and thawed. A. Chloramphenicol acetyl transferase; B. T7 lysozyme.

SDS/PAGE (Fig. 2, lanes 2, 4, 5 and 7). In addition, control samples were sonicated four times for $30 \mathrm{~s}$ at $0^{\circ} \mathrm{C}$ (Fig. 2, lanes 3 and 6). The results showed that the presence of T7 lysozyme did not interfere with the target SSB protein expression, and that the cell disruption was facilitated by the freezing-thawing treatment.

In summary, the developed freeze-thaw method for disintegration of $E$. coli cells producing T7 lysozyme used in pBAD expression systems is very simple and rapid and its efficiency for small volume samples is comparable to the efficiency of sonication.

\section{Acknowledgements}

We thank Pawel Filipkowski for the pBADMHADgeSSB plasmid. The pLysN plasmid is available on request from the Department of Microbiology at Gdańsk University of Technology (kur@chem. pg.gda.pl).

\section{REFERENCES}

Bollag DM, Rozycki MD, Edelstein SJ (1996) In Protein Methods, pp 27-43. Wiley-Liss Inc., New York.

Filipkowski P, Duraj-Thatte A, Kur J (2006) Arch Microbiol 186: 129-137.

Studier FW (1991) J Mol Biol 219: 37-44. 